\title{
Effective Approach to Promote the Internationalization of Shaanxi Universities in the Background of "Belt and Road" Initiative
}

\author{
Dapeng Ren ${ }^{1}$, Fengxiang Jiang ${ }^{2}$ \\ ${ }^{1}$ Xi'an Eurasia University, Xi'an, Shaanxi, 710065 \\ ${ }^{2}$ Xi'an Peihua University, Xi'an, Shaanxi, 710125
}

Keywords: “Belt and Road” Initiative; Shaanxi universities; effective approach

\begin{abstract}
Under the national implementation of the "Belt and Road" strategy, Shaanxi's higher education ushered in a rare opportunity for development, but also faced with a series of challenges and practical issues. In the face of new opportunities and challenges, Shaanxi's higher education should be guided by the "Five Development Concept," based on the concepts of "Three Communities" and "Five Links," and be diversified by levels of countries and regions along the "Belt and Road". In the areas of education, science and technology, culture, and other fields, all aspects of exchanges, cooperation and two-way interactions have been promoted. The level of internationalization of various colleges and universities at all levels in Shaanxi has been promoted, and the development of higher education in Shaanxi has been promoted.
\end{abstract}

\section{Introduction}

With the advancement of opening up and globalization, our country's influence and discourse in the international community have continuously increased. Since 2013, the implementation of the "One Belt and One Road" initiative has brought new opportunities for the development of higher education in China. Higher education institutions are an important symbol of the soft power of a country and a nation. The internationalization of higher education is a hot research issue in the education field in the past two decades. Major developed countries, such as the United States, the United Kingdom, and Australia, have actively promoted the internationalization of higher education through various strategies and methods and have achieved remarkable results. Internationalization of higher education includes internationalization of educational concepts, internationalization of teachers and students, internationalization of courses, internationalization of scientific research, international cooperation in running schools, and internationalization of university management services. In China, the internationalization of higher education has made great progress. While the "One Belt and One Road" construction continues to advance and make substantial progress, the importance and urgency of continuing to promote the nationalization of higher education is also rising.

\section{The Significance of the Internationalization of Higher Education in the Background of "Belt and Road"}

The core content of "One Belt and One Road" lies in the existence and development of mutual communication between different civilizations and countries. The Silk Road on land and the Silk Road at sea are the best proofs of civilized exchanges and mutual understanding. The construction of "One Belt and One Road" brings new opportunities for world-wide dialogue and exchanges among civilizations. It also brings new opportunities for the internationalization of higher education. First, the level of China's foreign cultural exchanges has been raised. Promoting the internationalization of higher education not only conforms to the trend and trend of education development in the world today, but also is closely related to our country's adherence to the basic national policy of opening to the outside world and the promotion of soft power. For a long time, various governments have sought to promote the internationalization of higher education through a 
series of measures in response to political, economic and academic demands. The level and degree of internationalization have become an important dimension for measuring and evaluating institutions of higher education and are therefore increasingly valued. "Overseeing today's global higher education institutions, we usually find that there is already a consensus on the specific measures to promote internationalization and internationalization of higher education."[1] The development of contemporary countries urgently requires the internationalization of education. The internationalization of education is the need to promote economic prosperity, enhance national innovation capabilities, and enhance national competitiveness. Globalization requires that the "global quality" of talents and global employability, and the ability to cultivate high-end talent with a global perspective, is one of the development goals pursued by university education in the world today. Secondly, the improvement of the level of university education requires constant improvement of the school's own international level. Internationalization is an important means to improve the quality and competitiveness of universities. Cultivating students' international perspectives, leadership and skills, attracting outstanding scholars and students from around the world, and promoting international exchanges and cooperation have all played an important role in enhancing the teaching, research, and service capabilities of schools. Researchers at the University of Florida have shown through comparative experiments that students with international experience are more creative, and the expert on education internationalization Willian Maddux also confirmed this: "Students with international experience have better ability to solve problems. Creativity is more likely to create new products and careers, and it is easier to improve and progress."'[2] Internationalization is very important for research universities, especially high-level research universities. Through the internationalization of universities, universities can also serve their economic and social development in a more direct manner, besides the training and delivery of talents, the application and transformation of scientific and technological achievements, and can also serve international economic cooperation.

\section{Implementation of "Belt and Road" Strategy Provides New Historical Opportunities for Higher Education Development in Shaanxi}

The Central Asia, South Asia, and West Asia regions adjacent to Shaanxi Province are not only the priority areas for the "One Belt and One Road" strategy, but also the focus of China's higher education cooperation. However, in these regions, higher education is relatively weak, the resources for higher education are relatively lacking, and there is a strong demand for high-level higher education. Shaanxi Higher Education implements the strategy of going abroad for running schools, which has both realistic basis and development prospects. On the one hand, after many years of development, Shaanxi's higher education has strong educational capabilities and rich experience in running schools. It has obvious advantages and advantages. It can give full play to the superiority of higher education personnel in Shaanxi, output high-quality resources for Shaanxi's higher education, and build Shaanxi's higher education brand. On the one hand, Shaanxi universities can organize overseas campuses based on their own school characteristics and academic advantages, or set up vocational skills training centers with Chinese companies going out to meet local education and vocational training needs, and cultivate new generation of technical talents and industrial workers for local communities. .

Promoting educational and cultural exchanges and realizing people's common ground is the "five links" (when President Xi Jinping proposed the "five links" when he visited Central Asia, that is, policy communication, road connectivity, trade flow, currency circulation, and people-to-people links), and it is also important for countries along the route. The key to public opinion is the foundation. Countries in Central Asia, South Asia, Western Asia, and Shaanxi Province have extensive educational and cultural exchanges. For example, Kazakhstan has 80,000 Shaanxi "Donggan people", speaks Shaanxi dialect, eats mutton foam, wears traditional clothes, and sings There is no problem with language and communication and cooperation in Shaanxi folk songs. [4] The implementation of the "One Belt and One Road" strategy has provided rare opportunities for Shaanxi and Central Asia, South Asia, West Asia and other countries to carry out educational 
exchanges.

\section{Strategic Problems Existing in the Development of Higher Education in Shaanxi in the Context of "Belt and Road"}

The modern Silk Road, as a link for international communication, is open to any country or region. Under the "One Belt and One Road" strategic background, Shaanxi's higher education should rely on its strength for development, and its strength needs to be supported by abundant financial resources. Shaanxi's higher education is on the one hand the result of Shaanxi's regional economic and social development. On the other hand, it is also the result of the adjustment of the country's higher education strategic layout. This has caused the problem that Shaanxi's economic and social development is out of step with the development of higher education. The core competitiveness of Shaanxi's higher education is at the top of the western region and fourth in the country. [6] In 2015, Shanxi's total GDP ranked 15th in the country. [7] The funds for running higher education in provincial higher education in China are mainly financed by local government funding and tuition fees. While relying on strong economic power in the eastern region to invest heavily in local colleges and universities, Shaanxi Higher Education is facing relatively insufficient investment in education funds. pressure. Although local governments in Shaanxi are striving to ensure the financial expenditure on higher education and increase investment in higher education in recent years, it is still difficult to meet the funding needs for the rapid development of higher education. In 2014, the average expenditure on higher education in Shaanxi ranked 23rd in the country. ,[8] The conditions for running a school are lagging relatively behind the "One Belt and One Road" economically developed areas. How to rationally use limited basic resources and improve the effectiveness of the use of educational funds is a practical issue that must be addressed in response to the "One Belt and One Road" strategic challenge in Shaanxi's higher education.

The "One Belt and One Road" project focuses on "culture, tourism, trade, finance, transportation, and infrastructure" and requires a large number of professionals in engineering, international trade, project design and management, and languages. Although the subject coverage of Shaanxi's higher education is extensive, due to the impact of the planned economy and the industry's school-running system, the service is mainly oriented to national construction and industry needs. It does not fully consider the situation of local economic and social development in many years. Although continuous adjustments have been made in the development, the overall situation of "strong engineering, weak science, and lack of liberal arts” has not been fundamentally changed. The existing major disciplines are still mainly concentrated in the engineering, aviation, electronics, chemical, and other engineering fields. The regional economic structure of Shaanxi Province does not match, and it cannot meet the demand for the construction of "One Belt and One Road." The problem of "labor shortage" and "difficulty in employment" coexist at the same time. How to adjust the professional structure of existing disciplines, actively integrate the "One Belt and One Road" strategy, and broaden the channels for entrepreneurial employment are issues that need to be addressed urgently in Shaanxi's higher education.

\section{Ways of Promoting Internationalization of Higher Education under the Background of "Belt and Road"}

Focus on the use of modern educational information technology to promote internationalization. Education informatization has become a driving force and an important approach to the internationalization of education. Since the beginning of the 21st century, large-scale open online courses have attracted millions of "out-of-country students" worldwide and have become an international "first-rate university" providing quality education resources, new learning evaluation methods, and credits for academic qualifications. Education Channel [4]. Education informatization has become the trend of the times, and MOOCs will also mature and change the supply model and quality of higher education. Colleges and universities under the "One Belt and One Road" initiative should actively use this trend to create a proper path and give full play to the role of information 
technology. Using education informatization to promote internationalization, it is possible to acquire world-class quality resources at low cost, to nurture teachers and students in a local and international manner, and to promote their own curricula content to the world through this form. High-quality teaching resources enhance their own image. This is a feasible international strategy for many colleges and universities lacking funds and attractiveness. Not only that, the online learning credits and mutual recognition of academic credentials also remove barriers to the recognition of students' learning results worldwide, and provide support for students' global employment.

Promote international education through professional certification and qualification system construction. Taking professional certification and qualification system as the traction, and improving the quality assurance system as the basis to promote internationalization of running schools, is an important strategy for the internationalization of universities. Although starting from the standard to promote internationalization of running a school seems to deviate from the usual sense of internationalization, it captures the essence of internationalization. Professional certification is widely used in the international community to ensure and improve the quality of professional education. The implementation of professional certification in colleges and universities, on the one hand, guarantees the level and quality of professional talents. On the other hand, due to the international mutual recognition of professional certification, the trained personnel are practically in line with international standards.

In building the "One Belt and One Road" university cooperation community, Sichuan University actively promotes the establishment of a multilateral cooperation mechanism, integrates and shares resources with a number of well-known universities at home and abroad, and promotes cultural integration and collaborative innovation between universities along the country and region. Expand the international influence of Chinese universities. Sichuan University is the Chinese lead school of the regional coalition of the upper reaches of the Yangtze River in China and the Russian Federal District of the Volga River. It actively prepares for the construction of the "Colleges of Universities along the China-Russia two river basins" to jointly cultivate the economic and social development of the "Volga-Yangtze River" basin. Many qualified personnel make active contributions to the promotion of scientific and cultural exchanges between the two countries.

\section{Conclusion}

The "One Belt and One Road" education campaign is a long-term undertaking. How to continuously improve the level of education opening to the outside world and continue to strengthen the ability to serve the "One Belt and One Road" initiative is a major real-world test for the current domestic universities and colleges. It needs various aspects. Participants work together and collaborate together.

\section{Acknowledgment}

Fund Project: Results of the 2017 Higher Education Research Project of the Shaanxi Higher Education Institute.

Project Title:

An Effective Path to Promote the Internationalization Level of Shaanxi Universities in the "One Belt and One Road" Background; Project Number: XGH17184

\section{References}

[1] Zeng Manchao, Yu Zhan. Study on the Internationalization of Higher Education in China and Japan—_Based on the Analysis of Literature [J]. Educational Development Research, 2008 (21): 42-51.

[2] Zhou Nanzhao. Comparison of several national policies on educational internationalization and reflections on world situation [J]. World Education Information, 2013(4): 3-18. 
[3] Chen Zongyuan. Analysis of third-party electronic payment [J]. Financial Technology Times, 2012(7): 58-60.

[4] Bao Yanlong. P2P network lending platform derived model risk investigation and analysis --based on financial stability perspective [J]. Fujian Finance, 2016(2) : 44-46.

[5] Wu Xiaoguang, Cao Yi. On strengthening the supervision of P2P network lending platform [J]. Southern Finance, 2013(4): 32-35. 